\title{
The Role of CD3, CD20, CD30, and Ki67 Immunohistochemistries in Establishing Mediastinal Gray Zone Lymphoma Diagnosis in 24-years-old Female Patient
}

\author{
Frenky Hardiyanto HS ${ }^{1}$, Suryanti Dwi Pratiwi ${ }^{1}$, Dini Rachma Erawati ${ }^{2}$, Artono Isharanto ${ }^{3}$, Diah \\ Prabawati Retnani ${ }^{4}$, Herwindo Pudjo ${ }^{5}$ \\ ${ }^{1}$ Departement of Pulmonology and Respiratory Medicine Faculty of Medicine Brawijaya University, Dr. Saiful Anwar \\ Hospital, Malang \\ ${ }^{2}$ Departement of Radiology Faculty of Medicine Brawijaya University, Dr. Saiful Anwar Hospital, Malang \\ ${ }^{3}$ Departement of Thoracic and Cardiovascular Medicine Faculty of Medicine Brawijaya University, Dr. Saiful Anwar \\ Hospital, Malang \\ ${ }^{4}$ Departement of Anatomic Pathology Faculty of Medicine Brawijaya University, Dr. Saiful Anwar Hospital, Malang \\ ${ }^{5}$ Departement of Internal Medicine Faculty of Medicine Brawijaya University, Dr. Saiful Anwar Hospital, Malang
}

\begin{abstract}
Introduction: A woman with complaints of shortness of breath, cough, fever, night sweating, decrease of body weight and swelling in face, neck and right arm. Chest x-rays and ct thorax revealed a mass in mediastinum.

Case Description: Patient is a 24 years old female with complaints of shortness of breath, cough, fever, night sweating, decrease of body weight and swelling in face, neck and right arm. Chest x rays and CT thorax revealed a mass in mediastinum. Open biopsy on right neck mass and transthoracic FNAB resulting of chronic inflammation, so the patient was diagnosed with glandular tuberculosis and Mediastinal Tumor. Patient was getting worse after one month consuming OAT. Patient was consulted to Cardiovascular and thorax Surgery Department. Patient was performed thoracotomy and debulking. Anatomical pathology was examined from debulking mass, the result of immunohistochemistry was found nodular mediastinal gray zone lymphoma.

Discussion: this case it is very difficult to enforce the diagnosis. Patients have done neck FNAB, transthoracic FNAB, open biopsy right neck mass and FOB have not been able to establish diagnosis. Until finally done thoracotomy and debulking in this patient, from immunohistochemistry results obtained nodular sclerosis Hodgkin lymphoma. Collaboration from pulmonologist, radiologist, cardiovascular and thorax surgeon, and patology anatomy specialist is needed to confirm the diagnosis in these patients.
\end{abstract}

Keywords: mediastinal tumor, mediastinal gray zone lymphoma

MRJ 2020; 2(2): 101-117

\footnotetext{
*Corresponding author:

Frenky Hardiyanto HS (frenkyhardiyanto@gmail.com)

Departement of Pulmonology and Respiratory Medicine Medical Faculty of Brawijaya, Dr. Saiful Anwar Hospital, Malang
} 


\section{Background}

Tumours in mediastinum could be classified as benign and malignant, one differs in treatment and prognosis than the other. ${ }^{1}$ Tumours in mediastinum rarely occurs, however both frequence and prevalence of malignant lesion tend to incline. Overall, prevalence of mediastinal tumour in adult is $1 \%$. Mediastinal tumour could occur as either primary or secondary. Primary tumour originates fom tissue/organ in mediastinum; such as thymus, neurogenic cell, germinal cell, and mesenchymal tissue. Secondary tumour has greater frequency, as malignancy more often spread via lymphatics originating from the lungs or infradiaphragmatic organs such as pancreas, gastroesophageal, and testicular. Mediastinum tumor most frequently occurs on $3^{\text {rd }}$ to $5^{\text {th }}$ decade. $54 \%$ of mediastinal tumour occurs in anterior, $20 \%$ in media $20 \%$, and $26 \%$ of mediastinal tumour happens in posterior. $^{2}$

$40 \%$ cases of mediastinal tumour is asymptomatic, being more frequently identified in screening studies or as an incidental radiologic finding. $60 \%$ of the cases often produce symptoms due to compression or direct invasion of mediastinum structure and paraneoplastic syndrome ${ }^{3} \quad$ Following symptoms could occur in mediastinal tumour; Cough (60\%), chest pain (30\%), fever (20\%) and shortness of breath (16\%). Symptoms in mediastinal tumour could be classified as local and systemic. Local symptom occurs due to invasion of tumour to surrounding tissue, thus lead to respiratory dysfunction, dysphagia, diaphragm and vocal cord paralysis, Horner syndrome, and superior vena cava syndrome. Systemic symptoms involves hormone, antibody, or cytokine release. ${ }^{4}$

Lymphoma or malignant lymphoma is a group of cancer cells in wherein lymphatic cells become abnormal and start to grow uncontrollably. Lymphoma growth could happen anywhere as lymph tissue are straggled in most of human body. ${ }^{5}$ Hodgkin Lymphoma has $25-40 \%$ prevalence of all lymphoma in developed countries. However in developing countries, particularly in Asian countries, Hodgkin Lymphoma has prevalence of 5-10\%. There are two peaks in the prevalence of Hodgkin Lymphoma, as in $2^{\text {nd }}$ and $3^{\text {rd }}$ decade as well as $6^{\text {th }}$ decade of age. The most commonly found subtype of Hodgkin Lymphoma is Nodular Sclerosis, with 
prevalence of $50-80 \%$ from the entirety of Hodgkin Limfoma. ${ }^{6}$

Diagnostic approach of Hodgkin Lymphoma relies on exhaustive anamnesis, which explore exposure, infection, night sweats, decrease of body weight for more than $10 \%$ within 6 months, physical examination of lymphatic system in particular (Lymph nodes, hepar, and lien with documented measurement), radiography and hisopathology examination, and immunohistochemystry examination, such as CD3, CD20, and CD30. ${ }^{7}$

\section{Mediastinal Gray Zone Lymphoma}

(MGZL) is a rare subtype of lymphoma with aggressive development. Diagnostic of MGZL is still a challenge due to its difficulty. The term 'gray-zone lymphoma' has been used to denote a new pathomorphological category of unclassified CB-cell lymphoma with intermediate features between diffuse diffuse large B-cell lymphoma (DLBCL) and classical Hodgkin`s lymphoma (CHL). It typically occurs in young male and presents as a solitary mediastinal mass, although often its clinical manifestation is not specific. ${ }^{8}$ To diagnose MGZL, a criteria in which included immmunohystochemistry scoring system examining CD20, CD15, and CD30 is needed..$^{9}$
MGZL requires a specific treatment approach, because of the fundamental differences in the development of $\mathrm{CHL}$ and traditionally more aggressive B - cell lymphoma. ${ }^{8}$ MGZL has poorer prognosis than PMBCL. ${ }^{9}$

Current study has evaluated he DAEPICH-R regiment in PMBL and has shown excellen prognosis, with very few paients requiring mediastinal radiation. The tratment approach for paients with bulky mediastinal classic hodgkin lymphoma nodular sclerosion (CHL-NS) should include radiation treatment. For patients with nonbulky CHL-NS, recent studies suggest that chemotherapy alone may be effective and that radiation therapy may be avoided. The optimal therapy for MGL has not been defined, but regimens like DA-EPOCH$\mathrm{R}$ are a reasonable approach. ${ }^{10}$

\section{Case Report}

A 24 year old female patient presents with shortness of breath since 5 months before admission, exacerbates since the last 7 days, along with cough with white phlegm since the past 1 months. History of squeezing chest pain, radiating to the back, arm, and neck since he past 5 months present. Neck and Arm often swelled, alleviated with consumption of furosemide. Painless neck lumps present since 
the last 2 weeks. Patient also suffers from fever since the last 1 month and night sweats. She complained $9 \mathrm{~kg}$ decrease of body weight since the last 5 months, but no abnormal appetite. Patient also often complains dizziness, dim vision, and has fainted 3 times dor the last week. Family history of tumour also present in her aunt, who suffers from breast cancer.

On 2014, patient had undergone surgery for a lump in her right neck, diagnosed with lipoma, and she has no complains ever since. On May 2017, patient was admitted to hospital with Mandible Abcess, but in thorax radiology a mass in mediastinum was found, thus diagnosed with Mediastinal tumour. On June 2017, patient was admitted to RSSA with anterior mediastinal tumour $\mathrm{dt}$ susp ivasive thymoma, along with complications: VCSS, bilateral pleura effusion, and a mass in her collar area dt Hodgkin lymphoma. On July 2017, patient had undergone FOB examination, trans-thoracal FNAB with USG and CT-scan guiding indicating chronic inflammation, and rapid molecular test showing negative tuberculosis infection. Patient thus diagnosed with glandular tuberculosis, and given tuberculosis therapy consist of 4FDC 3 tablets a day.

Physical examination had shown oedem on her face and right arm, and a hard, rubbery lump on her left neck, $0,5 \mathrm{~cm}$ in diameter. Her lung examination showed decrease of stem fremitus, dull percussion on right hemithorax, and decreased breath sound on right hemithorax

Her laboratory examination had shown anaemia $(\mathrm{Hb}=10,6 \mathrm{~g} / \mathrm{dL})$, increased neutrophil and monosit count $(71,6 \%$ and $14,3 \%$ respectively), decreased lymphocyte count $(13,4 \%)$, natrium $(131 \mathrm{mmol} / \mathrm{L})$ and kalium $(3,31 \mathrm{mmol} / \mathrm{L})$. Her CSA and NSE examination resulted in 14,90 and 35,38 respectively.

Lung function examination result :

Tabel 1. Lung function examination tetsted on 13 Juli 2017

\begin{tabular}{lccr}
\hline Lung Function & Actual & Prediction & $\%$ \\
\hline VC & 1,18 & 3,02 & $39,1 \%$ \\
FVC & 1,89 & 3,02 & $62,6 \%$ \\
FEV1 & 1,51 & 2,67 & $56,6 \%$ \\
FEV1/FVC & 79,89 & 88,22 & $90,6 \%$ \\
\hline Conclussion: medium restricition without obstruction & &
\end{tabular}

Radiology examination (Figure1,2,3) showed: 

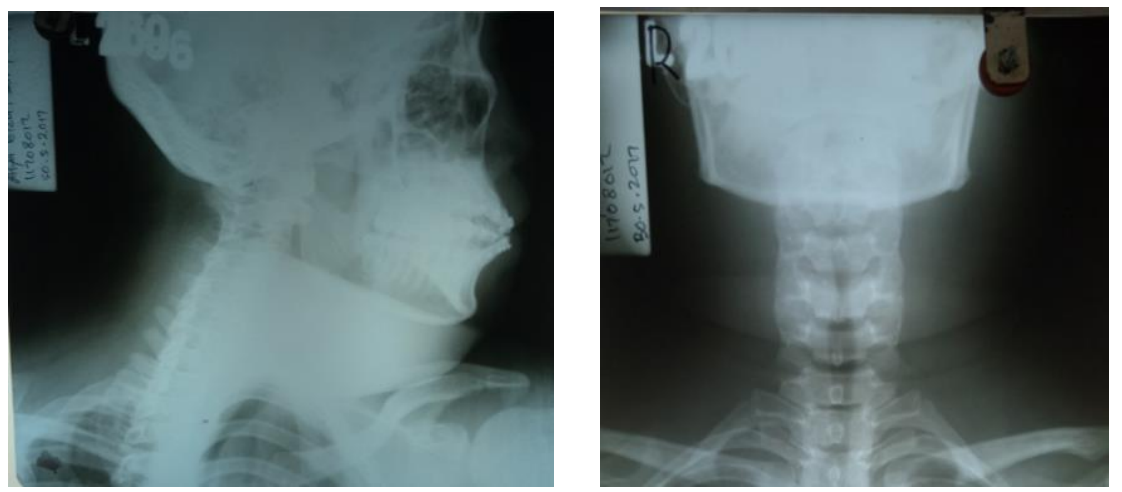

Figure1. Mandible XRay, AP and Lateral view taken on May 30, 2017 showed soft tissue edema from mandible to left and right neck area

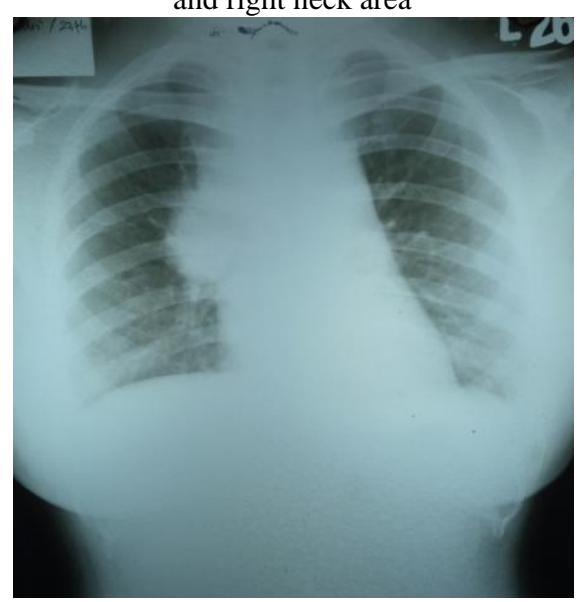

Figure 2. Thorax XRay taken on May 30, 2017 showed right mediastinal tumour with bilateral pleural effusion
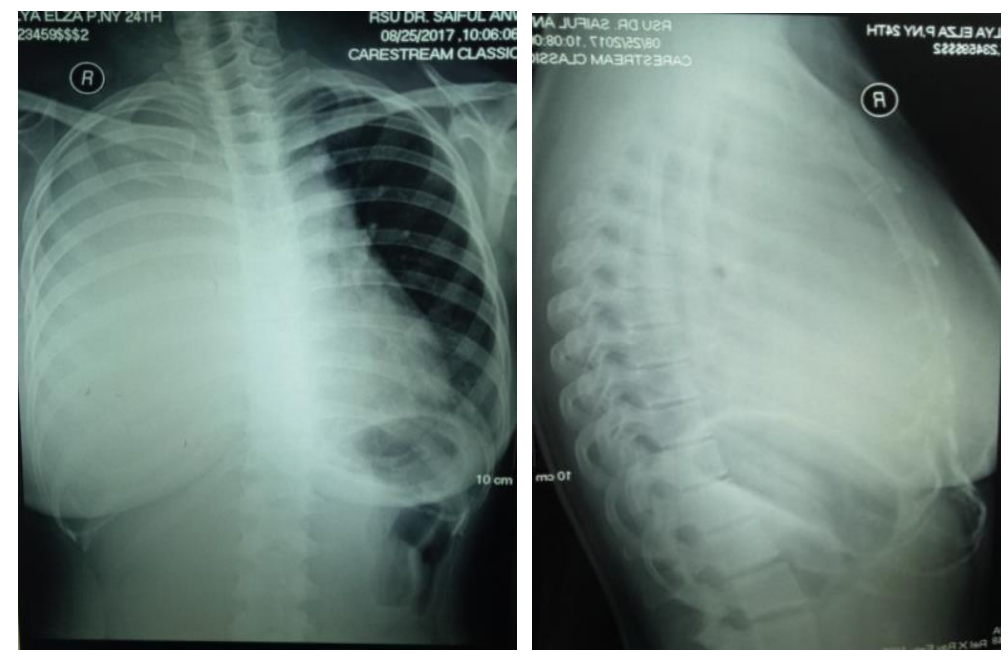

Figure 3. Thorax Xray, AP and Lateral view taken on August 28, 2017 showed suspected Lung tumour dd mediastinal tumour with right pleural effusion

Thoracic CT Scan (Figure 4) showed: 

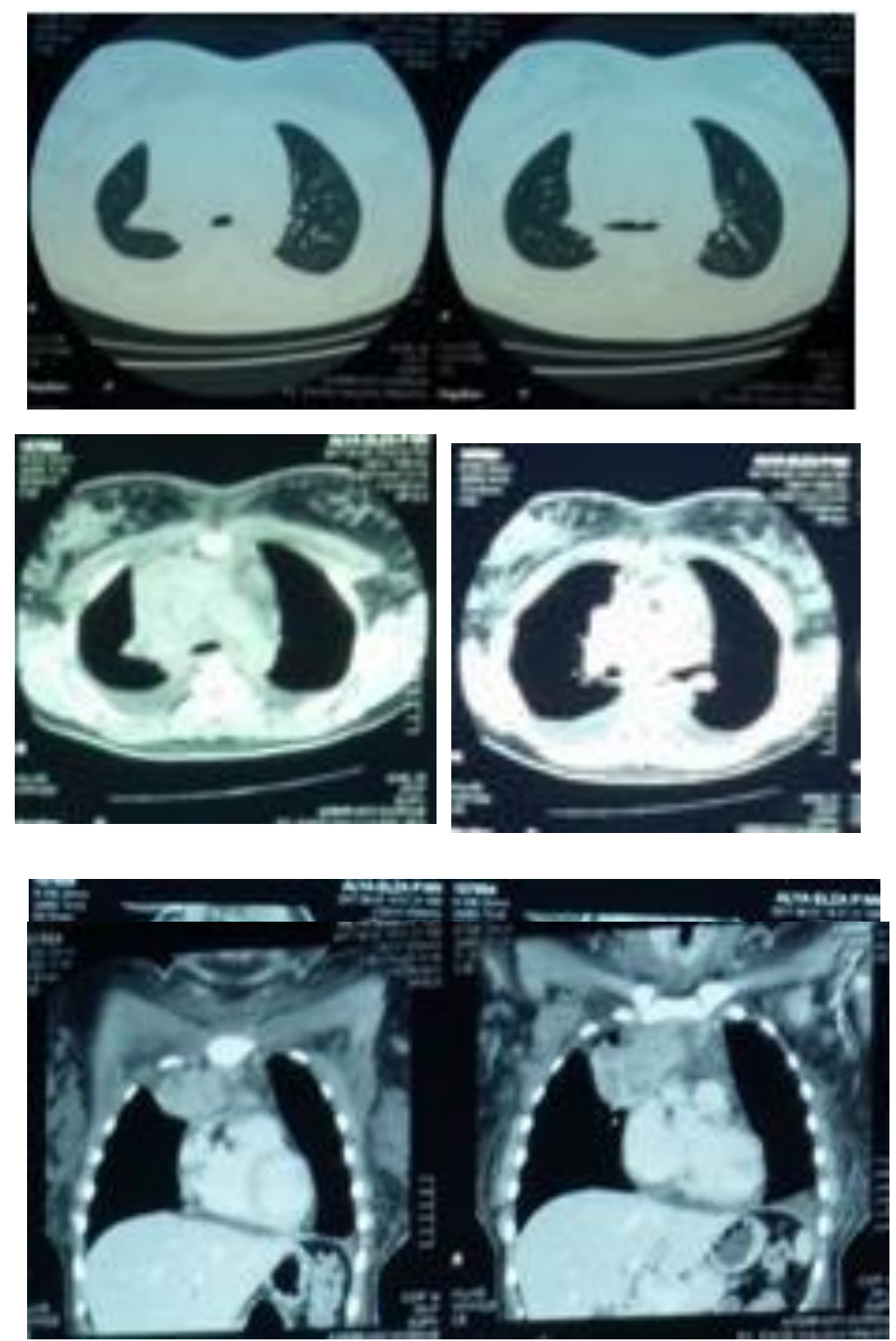

Figure 4. Thoracic CT Scan taken on June 5, 2017 showed anterouperior mediastinum mass, right-dominant, sugestif invasive thymoma dd thymic carcinoma wih bilateral pleural effusion. Technically it will be hard to proceed with FNAB because the mass showed encasing cellullar. 
Neck USG (Figure 5) showed:
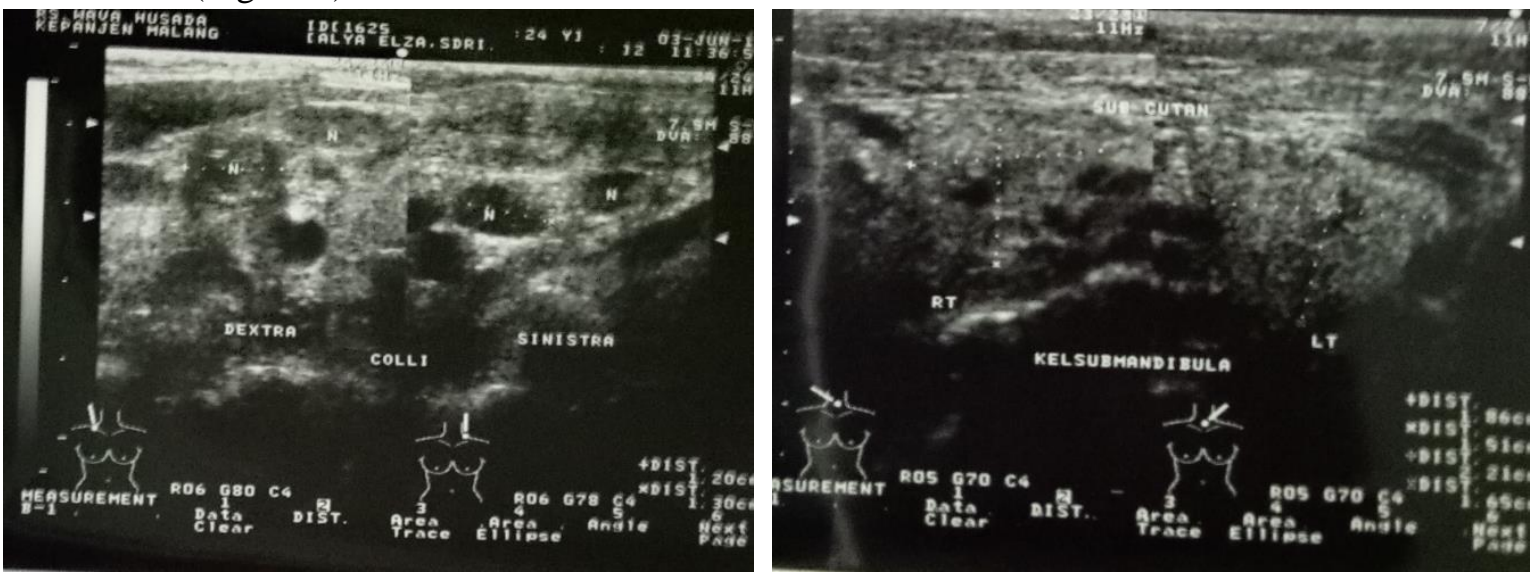

Figure 5. Neck USG on June 3, 2017 showed multiple lesion on bilateral colli region indicating lumphoma, soft tissue oedema on all mandibula and colli region

Abdominal USG (Figure 6) showed:
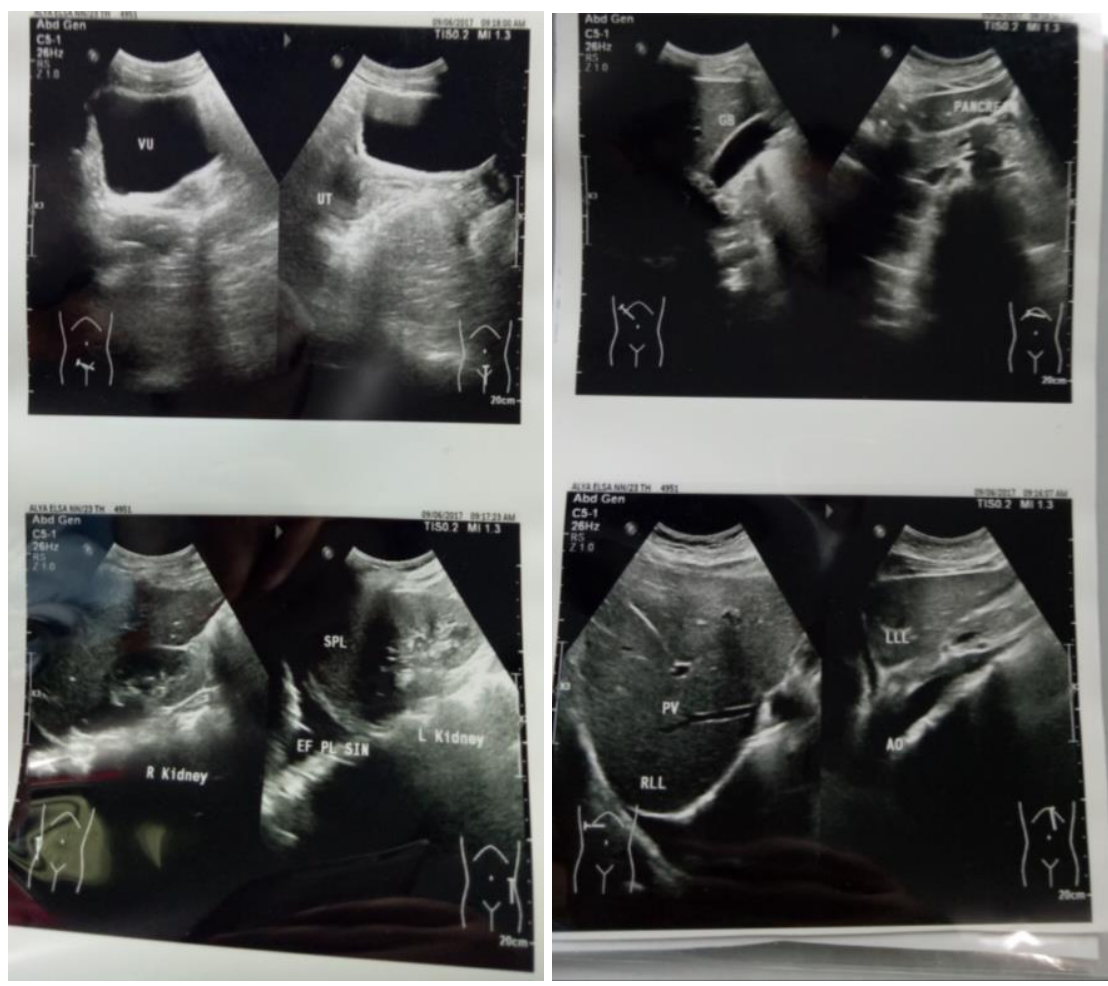

Figure 6. Abdominal USG on June 9, 2017 showed bilateral pleural effusion, metastasis node in hepar undetected

FNAB Right Colli Region on June 3, 2017

Macroscopic: 3 times puncture was

performed in multiple nodule in right neck

area with USG guiding, with extensive soft

tissue oedema, resulted in 3 DQ slides.
Microscopic: hypocele smear and minimal

distribution of degenerated lymphoid cells

with amorphous matrix background and the distribution of erythrocytes 
Conclussion: Multiple nodule on right colli region, FNAB on right collum with USG guiding: edematous tissue with degenerated lymphoid cell, not representative enough to determine diagnosis.

FNAB Colli Region on June 8, 2017

- 2 times punctures were performed on left supraclavicle nodule, $2 \mathrm{~cm}$ in diameter, mobile, hard and rubbery

- Microscopic: adequate smear showing loose cluster and distribution of cells with round nuclei

- $\quad$ spindle, pleomorphic, dan berinti kasar

Conclussion: Left Supraclavicular nodule;

FNAB:

- Hodgkin Lymphoma

- DD/ metastasis undifferentiated carcinoma

FNAB Trans Thoracal with USG Guiding on July 12, 2017:

- 2 times punctures were performed with USG and Trans-Thoracal CTscan guiding on anterosuperior mediastinum mass, solid necrotic, passing ICS II-III an IV-V, using spinal needle $25 \mathrm{G}$ for $2,5-5 \mathrm{~cm}$ in depth, acquiring 11 slides of diffquick and 7 slides of HE

- Microscopic: adequate smear showing distribution of oval nucleated cells, round cytoplasm and foamy, partly clustered, some squamae, inflammation cells (lymphocytes and neutrophils), fibrocytes, and necrotic material as well as fat matrix. There are also histiocyte and epithelioid cells which vaguely forms granulocyte.

- Conclussion: Anterosuperior mediastinum mass; FNAB with USG and CT-Scan guiding:

- Mass containing xanthoma cells

DD:

- Chroni granulomatic inflammation with fibrosis

- Fibroxanthoma

- Teratoma

\section{Optical fiber bronchoscopy (Figure 7)}

showed:

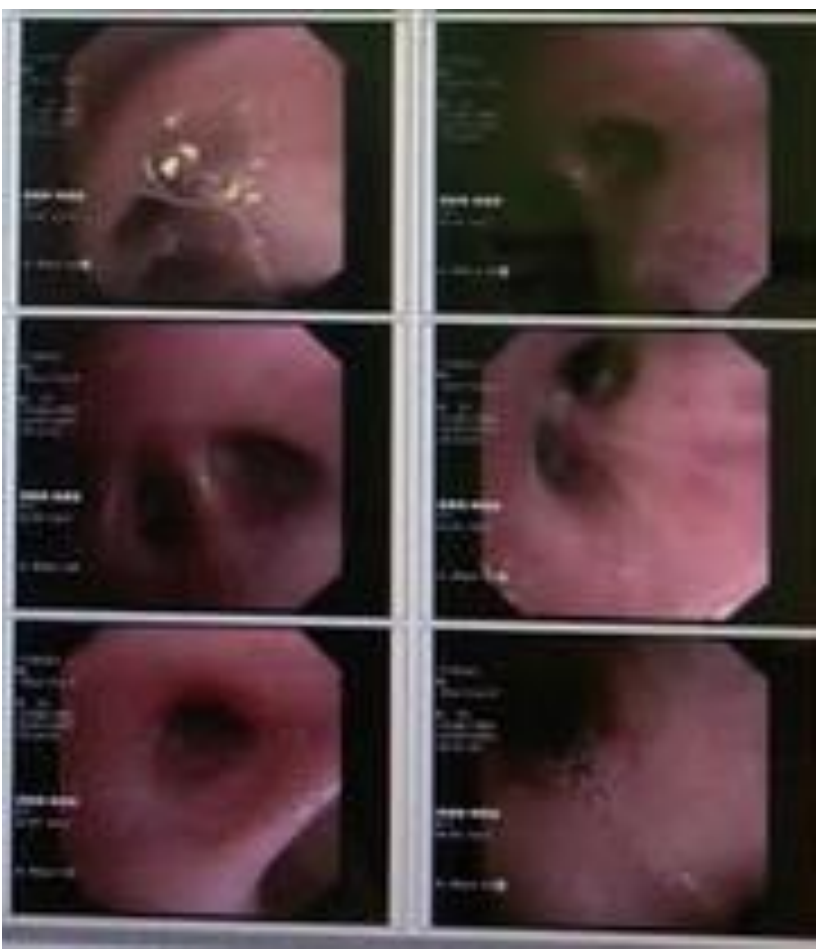

Figure 7. Bronchoscopy on 14 July 2017 showed stenotic infiltrative with inflammation process in the righ lung, malignany can not be excluded

Washing-Brushing Cytology on July 14, 2017

Class II:

- Malignant cells not found

- Epithelial cells were found with inflammatory changes

- Background: inflammatory cells: PMN, MN, histiosit 
FOB Fluid Culture on July 18, 2017

Culture: Serratia marcessens
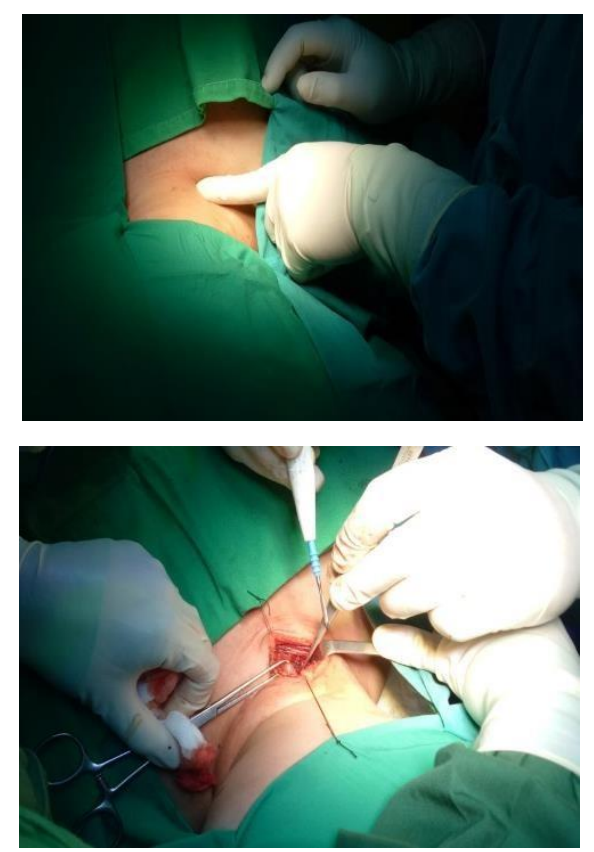

Sensitive to:

- Gentamicyn

- Ciprofloxacin

- Co-trimoxasole
Sputum Cytology on June 12, 2017

Conclussion: Class II
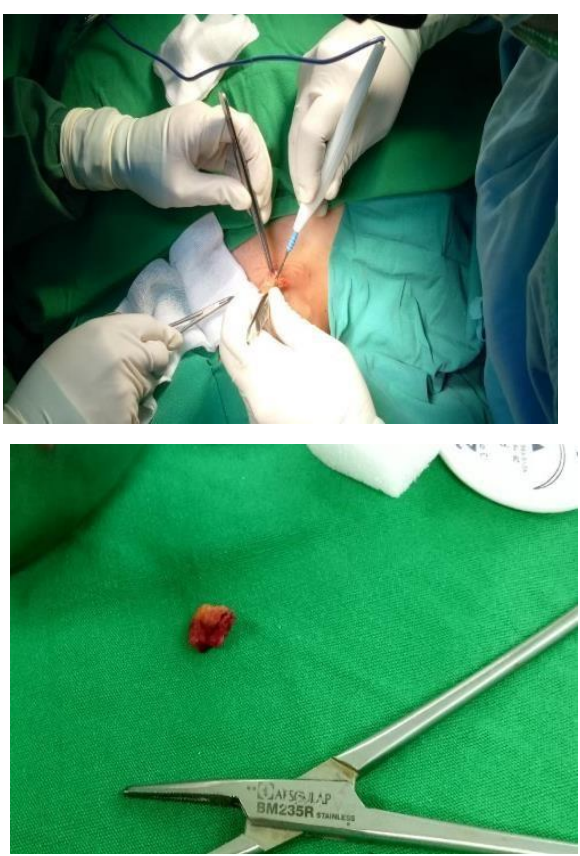

- Malignant cells not found

- Epithelial cells were found with inflammatory changes

- Background: inflammatory cells: PMN, MN, histiosit

Open Biopsi Right Colli Region Mass (Figure 8) showed:

Figure 8. Open biopsy process on right neck area mass on 20 June 2017, extracted is 4 lumps, 0,5-1 cm in diameter

\section{PA Open Biopsy}

Macroscopic:

- 4 grayish white lumps with diameters of $0,5 \mathrm{~s} / \mathrm{d} 1 \mathrm{~cm}$, solid. Partially processed into a cassette. Microscopic:

- Microscopic finding shows pieces of lymph node tissue, partially encapsulated, with several germinal centers, some appear fibrotic with many epithelioid cells, distribution of eosinophil and atypical cells NB: Gross and block recut is still done on every specimen. Please await for further response.
Gross and block recut results in microscopic finding:

- Small pieces of lymph node tissue, some appear fibrotic

- Focus of groups of histiocytes, eosinophil, and lymphoid cells

- Malignancy is not clearly visible Conclusion: Neck nodule, Open biopsy:

- Biopsy specimen suggesting chronic inflammation

Due to findings above, patient thus diagnosed with nodular sclerosis hodgkin lymphoma with complications: SVKS grade 2 
and bilateral pleural effusion. Patient was given intravenous furosemide $20 \mathrm{mg}$ - $20 \mathrm{mg}$ 0 , intravenous dexamethasone $3 \times 5 \mathrm{mg}$, nebulizer therapy with salbutamol+ipratropium bromide if any difficulties in breathing occurs, fentanyl patch $12,5 \mathrm{mg}$ changed every 3 days, paracetamol oral $3 \times 500 \mathrm{mg}$, codein $3 \times 10 \mathrm{mg}$, tuberculosis treatment using 4FDC 1x3 tablets, vitamin B6 x10mg, PRC transfusion 2 packs/day until
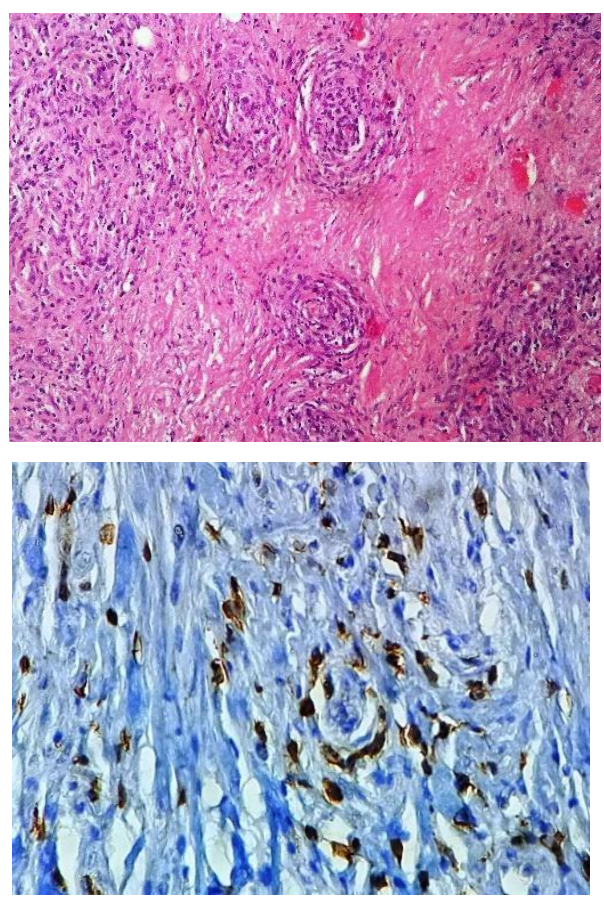

$\mathrm{Hb}>10 \mathrm{~g} / \mathrm{dL}$, thorax catheter implanted in patient's right lung on September 14, 2017 before mediastinum mass debunlking procedure was done, and continued with chemotherapy. Median Sternotomy and debulking procedure was done by cardiovascular thoracic surgery department before tumour specimen was taken for histopathology examination, resulting in Mediastinal Gray Zone Lymphoma (Figure 9).
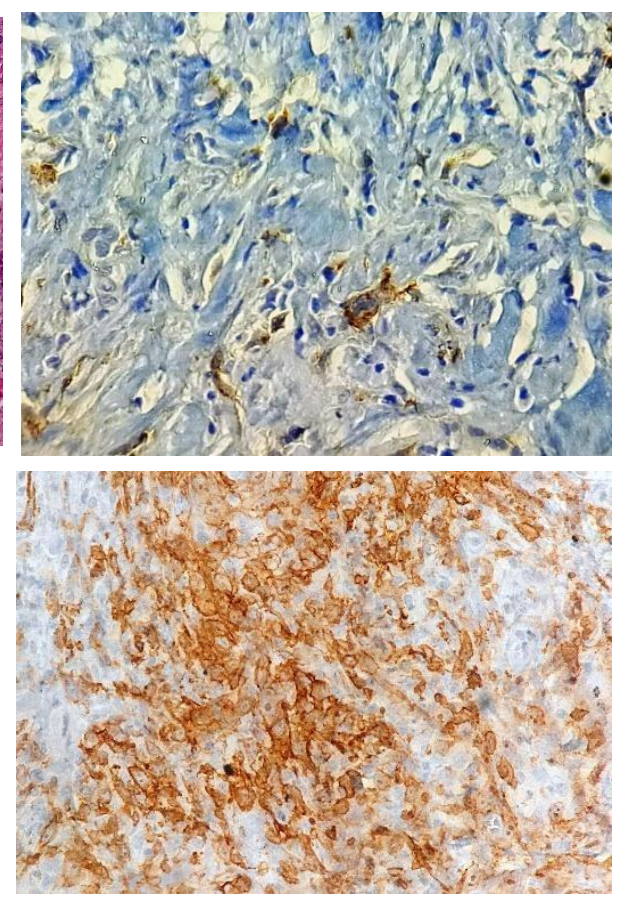

Figure 9. Pathology anatomy examination showed Mediastinal Gray Zone Lymphoma Caption : (1) granulomatous area (2) imunohistochemistry CD3 positive (3) imunohistochemistry CD30 positive; (4)

\section{Discussion}

In this case, 24 year old female presents with symptoms: shortness of breath, cough, chest pain, fever, decrease of body weight, swelling in face, neck, and right arm. These symptoms match literature reviews, in which was said that following symptoms could occur in mediastinal tumour: Cough $(60 \%)$, chest pain (30\%), fever (20\%) and shortness of breath (16\%). Symptoms in mediastinal tumour could be classified as local and systemic. Local symptom occurs due to invasion of tumour to surrounding tissue, thus lead to respiratory dysfunction, dysphagia, diaphragm and vocal cord 
paralysis, Horner syndrome, and superior vena cava syndrome. Systemic symptoms involves hormone, antibody, or cytokine release. Further classification as showed in table $2 .{ }^{4}$

Table 2 Local symptoms resulted from surrounding tissue compression Involved Anatomical Structure Local Symptoms

Bronchus/trachea

Esophagus

Vertebral column

N. laryngeal recurrent

N. phrenicus

Ganglion stellata

Vena cava superior

Patient had undergone chest $\mathrm{x}$-ray examination and mediastinum mass was found. CT-scan examination further found rightdominant anterosuperior mediastinum mass , suggestive invasive thymoma. DD/ Thymic carcinoma, bilateral pleural effusion. Literatures had shown frequency of mediastinal tumour in Indonesia, data taken from cardiothoracic surgery department of Persahabatan Hospital, Jakarta, and dr. Sutomo Public Hospital in Surabaya. During 19701990, Persahabatan Hospital had undergone 137 surgeries, in which following cases were Table 3. Mediastinal tumour classification based on location ${ }^{11}$ 3.

Shortness of breath, atelectasis, hemoptysis,
postobstructive pneumonia.
Dysphagia
Paralysis
Dysphonia, vocal cord paralysis
Diaphragm paralysis
Horner syndrome
Superior vena cava Syndrome

found: $32,2 \%$ teratoma, $24 \%$ thymoma, $8 \%$ tumours of nerve tissue, 4,3\% lymphoma. Data from dr. Sutomo Public Hospital had shown $67 \%$ cases of anterior mediastinal tumour, $29 \%$ cases occurs in medial, and $25,5 \%$ cases were posterior mediastinal tumour. Oversea studies had shown that tumour types which are prone to be found in anterior mediastinal tumour are lympoma, thymoma, and germ cell tumor. ${ }^{1}$ In Mediastinal tumour classification based on location, it was still possible to find lymphoma in anterior mediastinum as classified on table 


\begin{tabular}{lll}
\hline Anterior Mediastinal Tumour & Medial Mediastinal Tumour & $\begin{array}{c}\text { Posterior Mediastinal } \\
\text { Tumour }\end{array}$ \\
\hline Thymoma & Lymphoma & Nerve tissue tumour \\
Germ Cell Tumor & Pleuroperichardial cyst & Neurilemoma \\
Lymphoma & Mediastinal Granuloma & Neurofibroma \\
Lymphangioma & Hamartoma lympoid & Schwanoma maligna \\
Hemangioma & Mesotel cyst & Ganglioneuroma \\
Lipoma & Neuroenterik cyst & Ganglioneuroblastoma \\
Fibroma & Paraganglioma & Neuroblastoma \\
Fibrosarcoma & Phaeochromocytoma & Paraganglioma \\
Thymic Cyst & Thoracic duct cyst & Phaeochromocytoma \\
Parathyroid adenoma & & Fibrosarcoma \\
Thyroid aberrant & & Lymphoma \\
\hline
\end{tabular}

Patient thus underwent neck FNAB, followed by open biopsy, suggesting chronic inflammation, Transthoracic FNAB showing mass containing xanthoma cells dd/ chronic grabulomatic inflammation with fibrosis, fibroxanthoma, and teratoma. Afterwards patient underwent FOB examination. These steps align with literature showing diagnostic algorithm of mediastinal tumour without emergency features, involving radiology, endoscopy, histopathology, and laboratory examination, as well as explorative thoracotomy as shown in figure 10 .

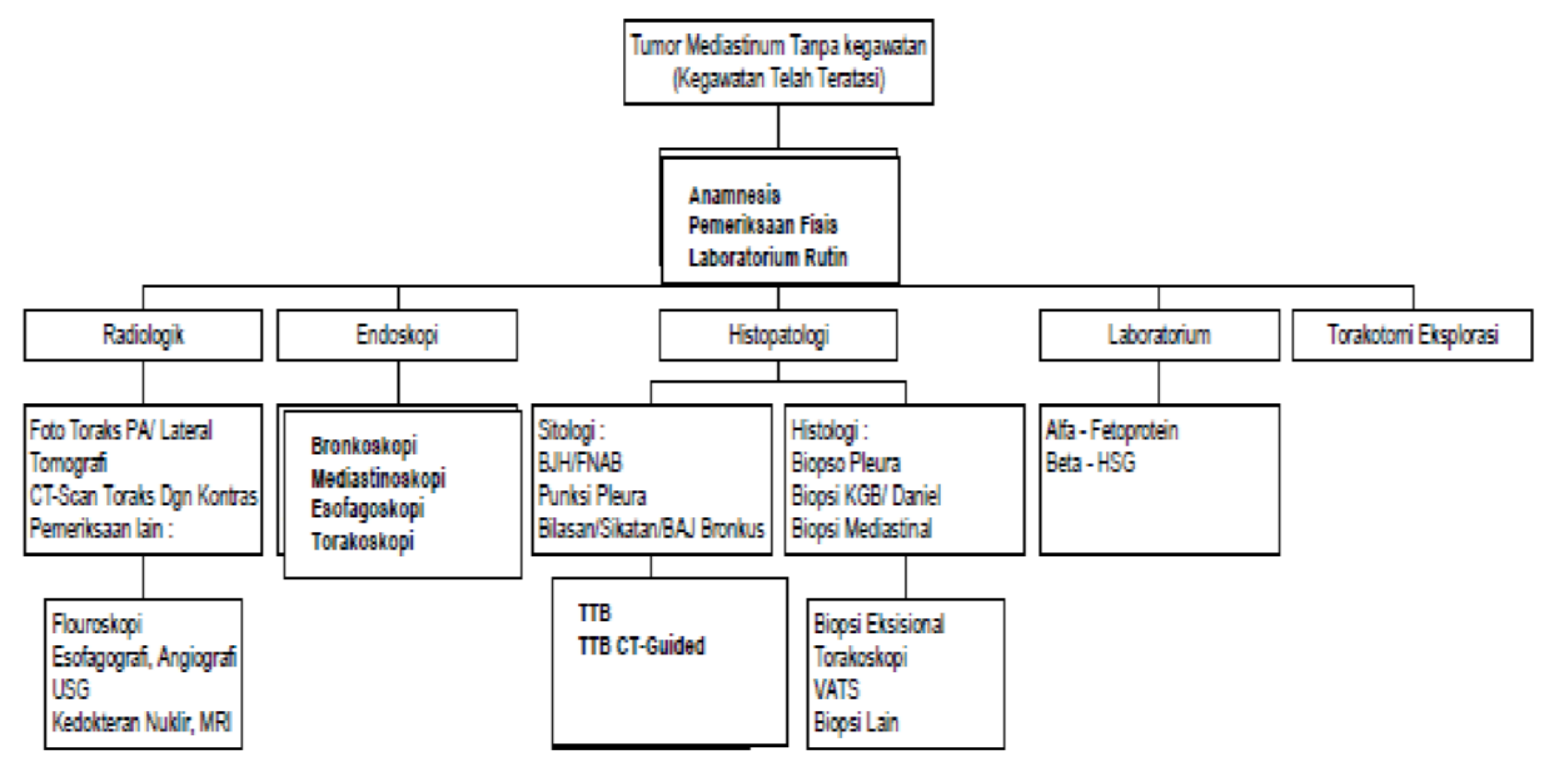

Figure 10. Diagnostic Algorithm of Mediastinal Tumour without emergency features ${ }^{1}$

On July 24 , 2017, patient came to pulmonary clinic in Saiful Anwar Public Hospital.
Anamnesis had indicated shortness of breath, chest pain, cough for more than 2 weeks, fever, 
night sweats, and decrease of body weight. Rapid Molecullar Test had showed MTB not detected. Open biopsy and PA examination of right neck mass suggested chronic inflammation, FNAB from mediastinal mass resulted in xanthoma $\mathrm{dd} /$ chronic grabulomatic inflammation with fibrosis, fibroxanthoma, and teratoma. Patient was diagnosed with glandular tuberculosis and underwent tuberculosis therapy; 4FDC $3 \times 1$. This approach align with literatures wherein symptoms in patient with TB include respiratory dysfunction such as shortness of breath, chest pain, cough for more than 2 weeks, and present systemic symptoms such as fever, night sweats, and decrease of body weight. FNAB from mediastinal mass found chronic granulomatic inflammation. Literatues had indicated that granulomatic inflammation could appear as infections, as in toxoplasmosis, tuberculosis, sarcoidosis, atypical bacterial infection, or neoplasm as in lymphoma, metastase carcinoma, as shown in figure $11 .{ }^{12}$

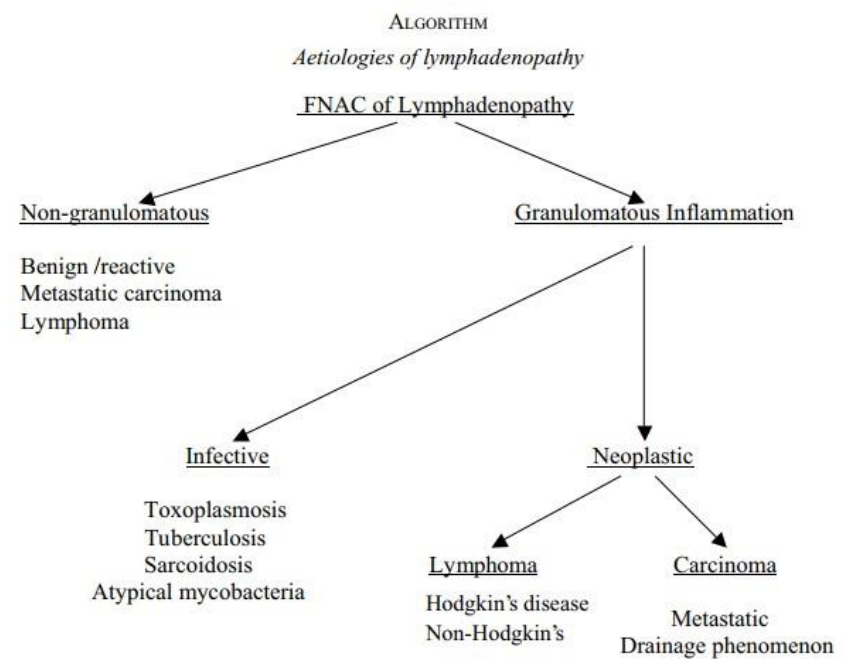

Figure 11. Etiology of lymphadenopathy 12

Patient was readmitted in Saiful Anwar Public Hospital on September 7, 2017. complaining shortness of breath since the last 5 months, exacerbating te past 7 days. Productive cough with white phlegm presents since the last month, after being admitted to hospital in July. Squeezing chest pain presents since the last 5 months, radiating to her back, arm, and neck. Her arm and face often swell, alleviated by consuming furosemide. Painless lump in neck present since the last 2 weeks, progressive in size. Her chest X Ray indicating exacerbation with massive pleural effusion on her right chest. TB drugs were stopped in accordance with her deteriorating condition. It can be inferred fom her worsening condition after consuming TB therapy for a month that granulomatic inflammation from FNAB is not due to tuberculosis. Granulomatic inflammation could appear as infections, as in toxoplasmosis, tuberculosis, sarcoidosis, atypical bacterial infection, or neoplasm as in lymphoma, metastase carcinoma, as shown in figure $11 .{ }^{12}$ 
On September 13, 2017, patient underwent thoracotomy and mediastinum mass debulking, as well as neck area biopsy. Temporary pathological result during surgery was suspect thymoma, but reexamination was soon to follow. Specimen taken from open biopsy of the neck and mediastinum was sent for genxpert examination, and had indicated no MTB detected. Thoracotomy procedure align with literature showing diagnostic algorithm of mediastinal tumour without emergency features, involving radiology, endoscopy, histopathology, and laboratory examination, as well as explorative thoracotomy as shown in figure 10 previously mentioned, moreven no other algorithm could be used for diagnosis ${ }^{1}$.

Immunohistochemistry examination was done on sample taken from mediastinal mass debulking previously sent to Pathology Anatomy laboratory using CD30, CD20, KI67, S100, CD15, CD3, CD68 antibody panels. CD30 examination was positive on atypical cells, Ki67 indicating high proliferating index $(>70 \%), \quad$ CD20 was positive, CD3 was positive. These result align with literature in which immunohistochemistry examination on \ Mediastinal Gray Zone Lymphoma will result in positive CD20, and CD30. ${ }^{9}$

In accordance to those data, it can be concluded that surgery result was Mediastinal Gray Zone Lymphoma. HistoPA result differs from previous neck open biopsy and Transthoracic FNAB which suspected thymoma dd/fibroxanthoma. This difference could occur due to fine needle biopsy could still not represent tumour cell.

In this case, immunohistochemistry examination and mediastinum mass debulking resulted mediastinal gray zone lymphoma. Literatures had mentioned that mediastinal gray zone lymphoma often happens to young male. ${ }^{8}$ But in this case was a 24-year-old female.

Based on anamnesis and physical examination, shortness of breath, cough, past history of swollen fface and neck followed by right arm in the past 2 months were present. Blood pools occuring in neck, these symptoms are local symptoms often found in almost all mediastinum tumour which started to compress surrounding tissue and superior vena cava. These symptoms correspond to literatures in which symptoms that could occur in patients with SVKS are conjunctival edema, CNS disorders such as headache, visual impairment, and decrease of consciousness. ${ }^{10}$ The most common symptoms are edematous face and neck (82\%), arm (68\%), shortness of breath (66\%), cough (50\%), and chest vein 
dilatation (38\%). Furthermore symptoms such as fullness in head, stridor, cyanosis on face and superior body parts, accompanied by normal capillary refill time, chest pain, dysphagia, dysphonia, headache, confusion, and syncope could also occurs. ${ }^{13,14}$ Based on her symptoms, patient could be categorised as SVKS grade 2 in accordance with table 4 .

Table 4. Grading System SVKS reccomended as CTCAE ${ }^{15}$

\begin{tabular}{llcl}
\hline Grade & Category & $\begin{array}{c}\text { Estimated } \\
\text { Incidence } \\
(\%)\end{array}$ & Definition \\
\hline 0 & Asymptomatic & 10 & $\begin{array}{l}\text { Radiographic superior vena cava obstruction in the } \\
\text { absence of symptoms }\end{array}$ \\
\hline 1 & Mild & 25 & $\begin{array}{l}\text { Edema in head or neck (vascular distention), cyanosis, } \\
\text { plethora }\end{array}$ \\
\hline 2 & Moderate & $\begin{array}{l}\text { Edema in head or neck with functional impairment (mild } \\
\text { dysphagia, cough, mild or moderate impairment of head, } \\
\text { jaw or eyelid movements, visual disturbances caused by } \\
\text { ocular edema) }\end{array}$ \\
\hline 3 & Severe & 10 & $\begin{array}{l}\text { Mild or moderate cerebral edema (headache, dizziness) or } \\
\text { mild/moderate laryngeal edema or diminished cardiac } \\
\text { reserve (syncope after bending) }\end{array}$ \\
\hline 4 & Life-threatening & 5 & $\begin{array}{l}\text { Significant cercbral edema (confusion, obtundation) or } \\
\text { significant laryngeal edema (stridor) or significant } \\
\text { hemodynamic compromise (syncope without precipitating } \\
\text { factors, hypotension, renal insufficiency) }\end{array}$ \\
\hline 5 & Fatal & $<1$ & Death \\
\hline
\end{tabular}

Thorax X Ray and CT scan examination indicated right dominant anterosuperior mediastinum mass, blurred border, and hard to distinct with vascular structure, mass ivasive to vascular gap. Compression to vascular, superior vena cava in particular, could result to Superior Vena Cava Syndrome. This corresponds to literature stating that lung cancer with mediastinal lymphadenopathy and primary mediastinum tumour was the most common cause of SVCS in the last 3 decades. ${ }^{10}$ Primary mediastinum tumour which could result to SVCS is lymphoma (65\%), medullar or follicular thyroid carcinoma, thymoma, teratoma, angiosargoma, and synovial cell carcinoma. ${ }^{16}$

Table 5. Most Common Cause of Superior Vena Cava Syndrome ${ }^{16}$

\begin{tabular}{|c|c|c|}
\hline \multicolumn{3}{|l|}{$\begin{array}{l}\text { Principal causes of superior vena } \\
\text { cava obstruction }\end{array}$} \\
\hline Malignant causes $\approx 95 \%$ of all causes & Benign causes $\approx 5 \%$ of all causes & Related to central venous line \\
\hline Lung carcinoma ( $(80 \%)$ & Cardiac & Pacemakers \\
\hline Small cell hystology & Aneurysma aorta or large arteries & Parenteral feeding lines \\
\hline Non small cell histology & Arteriovenous fistula & Hickman'lines \\
\hline Lymphoma $(\approx 15 \%)$ & Constrictive pericarditis & Dialysis line \\
\hline Hodgkins disease & Mediastinal fibrosis & Swan-Ganz catheter \\
\hline Non Hodgkins lymphoma & Sarcoidosis & LeVeen shunts \\
\hline $\begin{array}{l}\text { Metastatic Carcinoma: many primary } \\
\text { site reported }\end{array}$ & $\begin{array}{l}\text { Pulmonary } \\
\text { Mediastinal emphysema }\end{array}$ & \\
\hline Oesophageal carcinomas or leiomyoma & Tension pneumothorax & \\
\hline Thyroid carcinoma & Trauma & \\
\hline Thymoma and thymic carcinoma & Infection & \\
\hline Germ cell tumors & Arteritis & \\
\hline Breast carcinoma & Retrostemal goiter & \\
\hline Mesotelioma & Thrombosis & \\
\hline Leukemia: acute myeloid & Polycytemia rubra vera & \\
\hline Angioimmunoblastic lymphadenopathy & Cystic hygroma & \\
\hline Pseudotumours & Dermoid cyst & \\
\hline Histiocytosis X & Silicosis & \\
\hline Childhood tumors & & \\
\hline
\end{tabular}


On Thoracic Xray on May 30, 2017 and CT Scan on June 5, 2017 was founf bilateral preural effusion. On Thoracic Xray on May 30, 2017 was found massive right pleural effusion. This finding corresponds to literature, in which was stated that lymphoma is often followed by pleural effusion as complication. Disruption in lymphatic system and thoracal duct due to lymphoma could result to pleural effusion. Increase of peural intravascular pressure and sysemic vascular due to SVS could result to pleural effusion. Mediastinal mass invasion to right lung result in atelectasis of the right lung, further could cause decrease of pressure in pleura resulting to pleural effusion. Mediastinal mass could cause obstruction to mediastinal lymphatic, thus disturbs drainage system. ${ }^{17}$

On September 14, 2017, the patient underwent mediastinal tumor debulking. The surgery aims for diagnosis. During surgery, a mass was found attached to substernum, right lung, major vessel, resulted in the mass being unable to completely be removed, ergo the tumor debulking was performed. Patient's post-operative subjective result had improved, as in decrease of swelling in both right neck and arm. Further therapeutic approach was chemotherapy. Chemotherapy was done by Internal Medicine department in accordance with ABVD (Adriamycin, Bleomycin, Vinblastine, dan Dacarbazine) therapeutic regimen. This is in accordance to existing literature, in which a patient with mediastinal gray zone lymphoma is treated with chemotherapy. ${ }^{10}$

\section{Conclussion}

A 24-years-old woman presented with shortness of breath, cough, fever, night sweats, decrease of body weight, swollen fae, neck, and arm. Chest XRay and CT scan indicating anterosuperior mediastinal mass. Initial diagnosis was anterosuperior mediastinal tumour dd thymoma, teratoma, and fibroxanthoma accompanied by SVCS grade 2 . Right neck open biopsy PA and trans-thoracal FNAB indicated chronic inflammation. Thus the patient was diagnosed with Glandular Tuberculosis and was given tuberculosis therapy; 4FDC 1x3 tablets. Exacerbation occurs after a month in therapy, ergo the therapy was stopped.

Patient then underwent median sternotomy injury, mediastinal mass debulking, and right neck mass open biopsy.

Pathology anatomy with immunohistochemistry examination indicated mediastinal gray zone lymphoma. Pasca surgery, patient was given ABVD therapeutic regimen. Patient shows improvement and swelling on her face, neck, and arm decreased. 


\section{REFERENCES}

1. Perhimpunan Dokter Paru Indonesia. Tumor Mediastinum (Tumor Mediastinum Nonlimfoma), Pedoman Diagnosis dan Penatalaksanaan di Indonesia. Jakarta: Perhimpunan Dokter Paru Indonesia; 2003.

2. Travis WD. Pathology \& genetics tumours of the lung, pleura, thymus and heart. World Health Organization classification of tumours. 2004.

3. DeVita VT, Theodore S, Rosenberg SA. Devita, Hellman and Rosenbergs Cancer: Principles.

4. Cheng GS, Varghese Jr TK, Park DR. Mediastinal tumors and cysts. InMurray and Nadel's Textbook of Respiratory Medicine 2016 Jan 1 (pp. 1478-1495). WB Saunders.

5. Ford-Martin, Paula. Malignant Lymphoma [internet]. Healthline. 2005 [cited December 2017]. Available from: http://www.healthline.com/galecontent/malignan t-lymphoma/.

6. Kumar V, Abbas Abdul K, Fausto NR. Cotran pathological basis of disease 7th edition.

7. Higgins RA, Blankenship JE, Kinney MC. Application of immunohistochemistry in the diagnosis of non-Hodgkin and Hodgkin lymphoma. Archives of pathology \& laboratory medicine. 2008 Mar;132(3):441-61.

8. Dimitrova Y, Dimitrova K, Radev S, Dobrev V, Gerov V. A rare case and diagnostic process of gray zone lymphoma. Scripta Scientifica Vox Studentium. 2018 Apr 12;2:71.

9. Sarkozy C, Molina T, Ghesquières H, Michallet AS, Dupuis J, Damotte D, Morsschauser F, Parrens M, Martin L, Dartigues P, Stamatoullas A. Mediastinal gray zone lymphoma: clinicopathological characteristics and outcomes of 99 patients from the Lymphoma Study Association. haematologica. 2017 Jan 1;102(1):150-9.
10. Dunleavy K, Grant C, Eberle FC, Pittaluga S, Jaffe ES, Wilson WH. Gray zone lymphoma: better treated like hodgkin lymphoma or mediastinal large B-cell lymphoma?. Current hematologic malignancy reports. 2012 Sep 1;7(3):241-7.

11. Baum GL, Crapo JD. Baum s textbook of pulmonary diseases. Lippincott Williams \& Wilkins,; 2004.

12. Koo V, Lioe TF, Spence RA. Fine needle aspiration cytology (FNAC) in the diagnosis of granulomatous lymphadenitis. The Ulster medical journal. 2006 Jan;75(1):59.

13. Laskin J, Cmelak AJ, Meranze S, Yee J, Johnson DH. Superior vena cava syndrome. InAbeloff's Clinical Oncology: Fifth Edition 2013 Oct 22 (pp. 705-714). Elsevier Inc.

14. Grippi MA, Elias JA, Fishman J, Kotloff RM, Pack AI, Senior RM, Siegel MD, editors. Fishman's pulmonary diseases and disorders. McGraw-Hill Education; 2015.

15. James BY, Wilson LD, Detterbeck FC. Superior vena cava syndrome - a proposed classification system and algorithm for management. Journal of Thoracic Oncology. 2008 Aug 1;3(8):811-4.

16. Ugras-Rey S, Watson M. Selected oncologic emergencies. Rosen's Emergency Medicine: Concepts and Clinical Practice. 7th ed. Philadelphia PA: Elsevier. 2010:1592-4.

17. Medford A, Maskell N. Pleural effusion. Postgraduate medical journal. 2005 Nov 1;81(961):702-10.

18. Berthold D, Ghielmini M. Treatment of malignant lymphoma. Swiss medical weekly. 2004 Aug 21;134(3334).

19. Vinjamaram, S. Lymphoma, Non-Hodgkin [internet]. Medscape. 2010 [cited December 2017].

Available from:

http://emedicine.medscape.com/article/203399overview. 